\title{
Effective battery charging system by solar energy using C programming and microcontroller
}

\author{
Mohd Tariq ${ }^{1, *}$, Sagar Bhardwaj ${ }^{2}$, Mohd Rashid ${ }^{3}$ \\ ${ }^{1}$ M.Tech Student, Department of Electrical Engineering, Indian Institute of Technology, Kharagpur, India \\ ${ }^{2}$ B.Tech Student, Department of Electrical Engineering, Aligarh Muslim University, Aligarh , India \\ ${ }^{3}$ B.Tech Student, Department of Computer Science, Jamia Hamdard University, New Delhi , India
}

Email address:

tariq.iitkgp@gmail.com (M. Tariq)

To cite this article:

Mohd Tariq, Sagar Bhardwaj, Mohd Rashid. Effective Battery Charging System by Solar Energy Using C Programming and Microcontroller, American Journal of Electrical Power and Energy Systems. Vol. 2, No. 2, 2013, pp. 41-43.

doi:10.11648/j.epes.20130202.12

\begin{abstract}
Energy is one of the issues that is causing the most controversy as fossil fuels are the greatest pollutants and the greatest contributors to the greenhouse effect .The increasing importance of environmental concern, fuel savings and unavailability of power has led to the renewal of interest in renewable energies. It therefore stands to reason that developing countries whose energy consumption rate is increasing at a very fast rate should be investigating new energy systems based on renewable energies that do not pollute and which are inexhaustible such as the Solar system. In this paper a simple, reliable and effective solar panel charging system has been introduced consisting of a solar panel of desired size and shape. This solar panel is integrated with an embedded system ( which contains three modules i.e. de to ac converter, microcontroller/compiler module and charging output and a battery system).This embedded system regulates the electricity produced (after being converted to ac from dc) between the storage battery and charging output with the help of microcontroller which is programmed to combat the situations in presence and in absence of input supply and able to supply stored energy at night or in unavailability of solar source.
\end{abstract}

Keywords: Renewable Energy, Solar Energy, Embedded System, Battery, Microcontroller

\section{Introduction}

The rapid depletion of conventional fossil fuels and environmental concern have resulted in extensive use of renewable energy sources for electrical power generation. Energy is the convertible currency of technology. Without energy the whole fabric of society as we know it would crumble; the effect of a 24 hour cut in electricity supplies to a city shows how totally dependent we are on that particularly useful form of energy. Computers and lifts cease to function, hospitals sink to a care and maintenance level and the lights go out. As populations grow, many faster than the average $2 \%$, the need for more and more energy is exacerbated. Enhanced lifestyle and energy demand rise together and the wealthy industrialized economies which contain $25 \%$ of the world's population consume $75 \%$ of the world's energy supply [1].

The use of new efficient photovoltaic solar cells (PVSCs) has emerged as an alternative measure of renewable green power, energy conservation and demand-side management
[2]. Renewable energy is the only hope and it is the area of latest research which needs a revolution to make an effective solar panel charging system for the regulation of the flow of current to the desired output and saving the battery from receiving extra voltage and increasing the life.

\section{Modelling of PV Cell}

PV generators are neither constant voltage sources nor current sources but can be approximated as current generators with dependant voltage sources [3]. During darkness, the solar cell is not an active device. It produces neither a current nor a voltage. However, if it is connected to an external supply (large voltage) it generates a current ID, called diode current or dark current. The diode determines the $\mathrm{i}-\mathrm{v}$ characteristics of the cell. There are three different models of PV cells generally available. A moderate model of PV cell has been taken in this paper as shown in Figure1. 


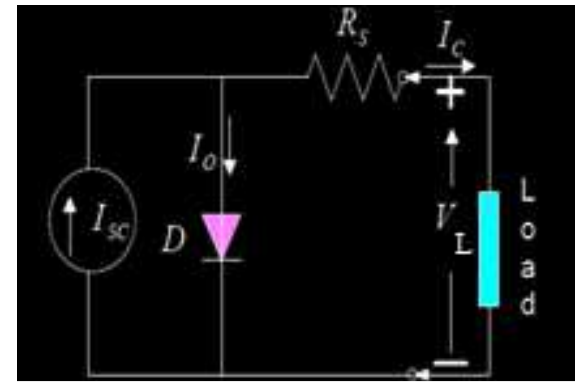

Figure.1. PV cell model.

The model consists of a current source ( Isc ), a diode (D), and a series resistance $\left(\mathrm{R}_{\mathrm{S}}\right)$. As the effect of parallel resistance $R p$ is negligible, it has been omitted in this model[4].

PV arrays are built up with combined series/parallel combinations of PV solar cells, which are usually represented by a simplified equivalent circuit model such as the one given in Fig. 1 and/or by an equation as in (1)

$$
\mathrm{V}_{\mathrm{L}}=\frac{A K T_{C}}{q} \ln \left(\frac{I_{S C}+I_{O}-I_{C}}{I_{o}}\right)-I_{C} R_{S}
$$

Where the symbols are defined as follows:

e: electron charge $(1.602 \times 10-19 \mathrm{C})$.

$\mathrm{k}$ : Boltzmann constant $(1.38 \times 10-23 \mathrm{~J} / \mathrm{oK})$.

Ic: cell output current, A.

$\mathrm{I}_{\mathrm{SC}}$ : photocurrent, function of irradiation level and junction temperature $(5 \mathrm{~A})$.

Io: reverse saturation current of diode $(0.0002 \mathrm{~A})$.

Rs: series resistance of cell $(0.001 \Omega)$.

Tc: reference cell operating temperature $\left(20^{\circ} \mathrm{C}\right)$.

$\mathrm{V}_{\mathrm{L}}$ : cell output voltage, $\mathrm{V}$.

\section{Problem Statement}

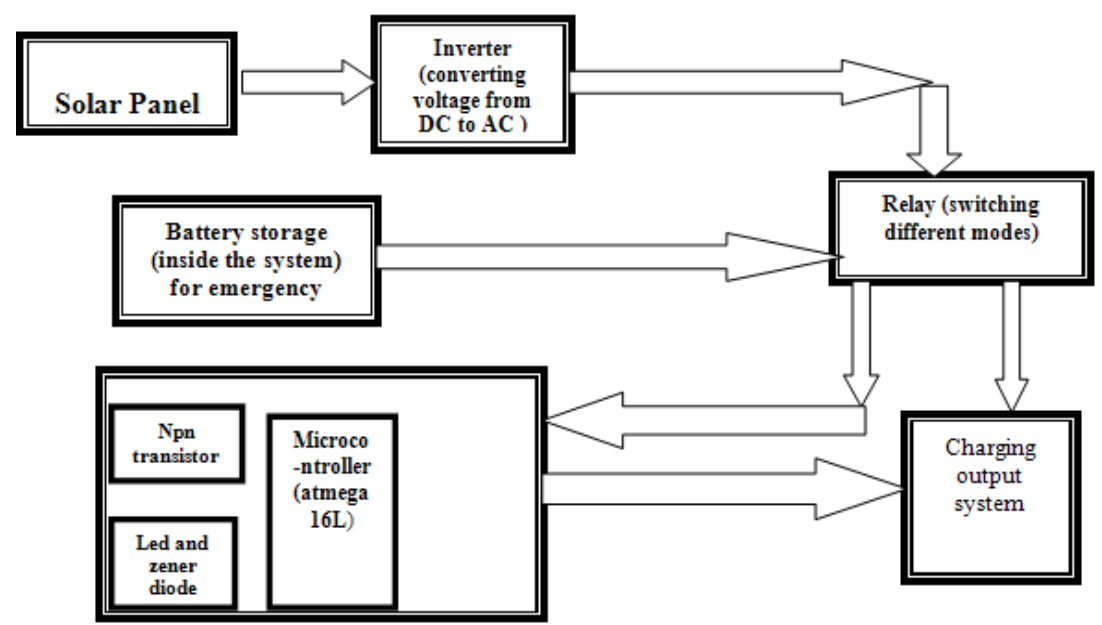

Figure.2. Block Diagram of the Proposed System.

Here the design shows the various connections inside the system taking place.

$>$ Input from the solar panel
A small effective system comprising of four modules, first the stepping down the de voltage from $\mathrm{Xv}$ to $\mathrm{Yv}$ (say) for the microcontroller process to take place, secondly inverting the dc to ac, followed by the relay action of switching and finally passing it to the microcontroller module where it is governed as per the situation of the battery of the module as well as of the system.

\section{Set Up}

The designed system will solve several of the situations where the solar panel is shown incapable and not worthy for the work. As the system switching the different modes of the battery in the system and in the applied area. Here is the general information describing the overall system, we get the supply from the solar panel system which is step down as per the requirement and inverted if needed which sends us to the next level of relay where the switching takes place as per the command of microcontroller. Considering the three situations in when solar panel is connected:

a) Firstly when the output is connected, in this case the current flows directly to the output, once the output requirements are fulfilled, it automatically switches to the next mode with the help of a zener diode being regulated by microcontroller and commanded to relay, fixed to a certain level and glowing the led for the same.

b) Secondly the switched mode transferred to the charging of the battery placed inside the system for emergency usage, follows the same function of charging and when fully charged to the level of Zener diode given it switches the current to the initial stage.

c) Thirdly the initial stage current not entering the system when both the stages are fulfilled prevent the further depletion of batteries which can be caused if extra current runs through them and increasing the life of the system. 
commands from microcontroller.

$>$ Micro-controller connected with the npn transistor

$>$ As soon as the battery of output is filled up the zener diode cut-off the supply and glow the respective led.

$>\quad$ And doing same for the system battery and glows the led after the zener diode cut off.

$>$ And finally when both the tasks are performed it returns the supply to the input point.

\section{Requirements}

1. Solar panel:- any solar panel as per the need and requirement.

2. A normal storage battery:- as per the model required

3. A microcontroller (atmel):- preferably atmega16L

4. A relay:- $12 \mathrm{~V} / 5 \mathrm{~V}$ or as per the requirement

5. invertor :- to convert dc to ac voltage

6. voltage chopper- LM317/7805

7. LED and Zener diodes :- signifying the battery is full and zener diode to cut off the supply.

\section{Microcontroller Programming}

The above algorithm is the key to be built in the micro controller which is regulating the different modes of the charging system:

P1-input port

P2-output port

while(1)//when input supply is there from solar panel

$\{$ If $(a==1) / /$ when output battery is not fully charged

$\{\mathrm{P} 2=0 \mathrm{xff}$;//opening port for the output $\}$

elseif $(b==1) / /$ when system battery not fully charged

$\{\mathrm{P} 2=0 \mathrm{x} 0 \mathrm{f}$;//opening supply for system battery $\}$

elseif $(\mathrm{a}=\mathrm{b}==0) / /$ when both the batteries are charged

$\{\mathrm{P} 2=0 \mathrm{x} 00 ; / /$ returning the input supply to the initial point $\}$ else

$\{\mathrm{P} 2=0 \times 00$;//or in any other condition the supply at input and not disturbing the system $\}$

While (0)//when solar panel supply not connected

$\{\operatorname{If}(b==1) / /$ system battery if charged $\}$

$\{\mathrm{P} 2=0 \mathrm{x} 0 \mathrm{f} ; / /$ supplying the charged system battery output to the output point .\}

This is a simple $\mathrm{C}$ programming which can be written in the microcontroller.

\section{Conclusion}

As discussed in the paper the proposed system will be very effective for solving several situations where the solar panel is incapable and not worthy for the work. The proposed effective charging system can be extended to any level, any set-up, which only involves the small embedded kit with the three essential modules empowering the renewable energy

\section{References}

[1] Fells I. The problem. In: Dunderdale J,( 1990) editor. Energy and the environment. UK: Royal Society of Chemistry.

[2] Abu Tariq, M. Asim, Mohd Tariq (2011) "Simulink based modeling, simulation and Performance Evaluation of an MPPT for maximum power generation on resistive load", 2nd International Conference on Environmental Science and Technology,Singapore.

[3] Khan, B.H., (2006), Renewable energy resources, TataMcGraw-Hill Publishing Company Limited, New Delhi, India.

[4] [Altas. I, A. M. Sharaf, 2007 “A photovoltaic array (PVA) simulation model to use in Matlab Simulink GUI environment.” IEEE I-4244- 0632 -03/07. 